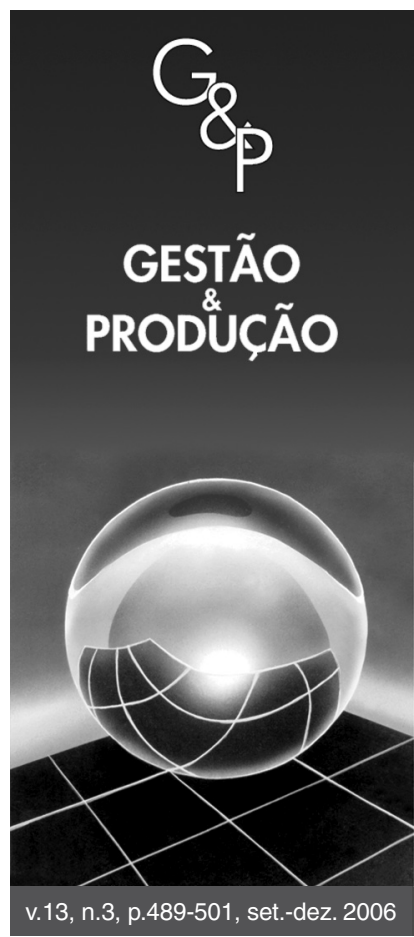

\title{
OPORTUNIDADES TECNOLÓGICAS E ESTRATÉGIAS CONCORRENCIAIS DE GESTÃO AMBIENTAL: O USO SUSTENTÁVEL DA BIODIVERSIDADE BRASILEIRA
}

\author{
Ana Flávia Portilho Ferro \\ Maria Beatriz Machado Bonacelli \\ Ana Lúcia Delgado Assad
}

Resumo

Recebido em 06/7/2006

Aceito em 22/11/2006

A biodiversidade tem sido apontada como um elemento de importância estratégica devido, entre outros fatores, ao seu potencial como fornecedora de matéria-prima para diversos setores da economia. Diante deste quadro, mas também do de destruição deste patrimônio, têm se inserido muitas das atuais estratégias de empresas, as quais vêm procurando acompanhar e aproveitar o desenvolvimento de novas oportunidades tecnológicas abertas pelos mercados de produtos obtidos de forma ambientalmente responsável. A incorporação de modelos sustentáveis de uso dos recursos é, portanto, vista como um diferencial capaz de gerar vantagens competitivas. Dessa forma, o presente trabalho apresenta e discute de que forma algumas empresas brasileiras vêm utilizando em suas estratégias competitivas o potencial da biodiversidade como forma de criar elou de aproveitar novas oportunidades e explorar novos nichos de mercado, apontando as principais vantagens e limitações encontradas neste tipo de estratégia. Para tanto, traz uma análise dos casos de quatro empresas nacionais atuantes no mercado de produtos obtidos de forma sustentável nos segmentos de fitoterápicos, cosméticos, extratos naturais e de manejo florestal. Parece claro que a incorporação dos preceitos do desenvolvimento sustentável no uso da biodiversidade é uma tendência que vem se fortalecendo, principalmente em setores altamente dependentes de matéria-prima advinda da biodiversidade. Neste contexto, destaca-se a importância da geração de inovações para atender à demanda por novas práticas e tecnologias, assim como da conformação de um ambiente institucional capaz de estimular a incorporação da variável ambiental por todo o setor produtivo.

Palavras-chave: inovações tecnológicas, desenvolvimento sustentável, produtos naturais, estratégias competitivas, responsabilidade ambiental.

\section{Introdução}

A diversidade biológica ou biodiversidade tem sido cada vez mais reconhecida como um dos elementos centrais para o desenvolvimento e bem-estar da humanidade e grande responsável pelo equilíbrio ambiental global. Embora apenas uma pequena parte de seus componentes tenha sido adequadamente estudada e seus benefícios futuros ainda não sejam totalmente conhecidos, tem-se valorizado cada vez mais sua capacidade de gerar benefícios socioeconômicos, devido ao seu potencial como matéria-prima para diferentes campos do conhecimento, como a medicina e diversos setores da indústria. No entanto, para que se possa explorar adequadamente este potencial, é necessário, antes de tudo, garantir a manutenção e disponibilidade destes recursos no meio ambiente, sendo assim fundamental a implementação de mecanismos de conservação ambiental (por conservação, entende-se o uso racional dos recursos, de modo a evitar riscos de extinção) e modelos de desenvolvimento sustentáveis.

Muitas empresas têm visto neste cenário uma oportunidade de negócio. A incorporação de modelos sus- 
tentáveis de uso e exploração dos recursos passa a ser visto como um diferencial capaz de gerar vantagens competitivas. Deste modo, estas empresas têm procurado integrar os princípios e práticas do desenvolvimento sustentável em seu contexto de negócio, conciliando as dimensões econômica, social e ambiental da sustentabilidade no aproveitamento do potencial da biodiversidade. No entanto, este tipo de estratégia requer investimentos e capacitação em inovação, seja esta tecnológica ou organizacional, interna ou em parceria. É neste contexto que se inserem, por exemplo, as atuais estratégias de algumas empresas nacionais atuantes em diferentes setores, como extratos naturais, cosméticos, perfumaria e higiene pessoal, as quais vêm procurando acompanhar e aproveitar o uso econômico da biodiversidade no desenvolvimento de novas trajetórias abertas por este mercado.

É comum essas empresas desenvolverem projetos junto às comunidades locais, constituindo parcerias para, por exemplo, realizar a extração da matéria-prima por meio de planos de manejo sustentáveis e garantir a autosuficiência econômica das comunidades. Vem mudando, portanto, a percepção da questão ambiental, tornando-se esse aspecto uma importante fonte de aproveitamento de oportunidades técnico-econômicas, em contraposição a concepções mais conservadoras, para as quais a preservação e/ou a não agressão ao meio ambiente incorre em custos adicionais e onera a produção.

Dessa forma, o presente trabalho tem como objetivo caracterizar e analisar este tipo de estratégia em quatro empresas nacionais - Natura, Centroflora, Orsa Florestal e Ybios -, apontando os principais gargalos encontrados, estando o foco na importância da geração de inovação, uma vez que o estudo desses casos mostrou que a implementação dessas estratégias apresenta complexidades de ordem operacional, organizacional e, principalmente, inovativa. A fim de solucionar estes gargalos, a formação de parcerias - desde a capacitação do fornecedor até a formação de redes de inovação para otimizar as atividades de pesquisa e desenvolvimento de novos produtos - foi apontada como um dos pontos cruciais na viabilização das estratégias.

$\mathrm{O}$ artigo está organizado em quatro seções. A primeira discorre sobre a relevância da biodiversidade e sobre a forma com que esta vem sendo valorizada e, ao mesmo tempo, ameaçada pela sociedade. A segunda parte aponta para as oportunidades oferecidas pelo uso sustentável da biodiversidade como estratégia competitiva. A terceira parte apresenta e discute os casos das empresas Ybios, Centroflora, Orsa Florestal e Natura. Finalmente, a quarta e última seção traz as considerações finais do artigo.

\section{Biodiversidade: crescente valorização}

A evolução da discussão em torno da relevância da biodiversidade pode ser entendida como um desdobra- mento do movimento ambientalista, uma vez que a diversidade biológica é um dos elementos centrais para o desenvolvimento e bem-estar da humanidade. A perda da biodiversidade é considerada preocupante por três razões básicas. Primeiramente, pela sua importância ética e estética. Em segundo lugar, há uma gama de serviços essenciais para o bom andamento da maquinaria da biosfera e para a manutenção de serviços de regulação prestados pelos ecossistemas naturais, dos quais muitas espécies são peças fundamentais. Tais serviços incluem a manutenção da composição gasosa da atmosfera e do clima, a geração e manutenção dos solos, controle das populações de pragas, polinização de culturas e fornecimento direto de alimentos. Finalmente, a biodiversidade já gerou imensos benefícios econômicos diretos ao homem na forma de alimentos, medicamentos, produtos industrializados e tem potencial para gerar muito mais (Wilson, 1994; Ehrlich e Wilson, 1991).

Este potencial da biodiversidade de gerar benefícios econômicos tem sido cada vez mais valorizado pelos meios acadêmico e industrial, uma vez que esta pode ser fonte de matéria-prima para a medicina e diversos setores da indústria, como o farmacêutico, alimentício, químico, de aditivos e também para a agricultura e horticultura. Arnt (2001) define a biodiversidade como "o cofre de um patrimônio químico inexplorado de remédios, alimentos, fertilizantes, pesticidas, cosméticos, solventes, fermentos, têxteis, plásticos, celulose, óleos e energia, além de moléculas, enzimas e genes em número quase infinito". Desse modo, a biodiversidade pode ser entendida como uma preciosa "biblioteca genética" mantida em seus ecossistemas naturais, na qual apenas uma pequena parte de seus componentes foi adequadamente estudada e cujos benefícios futuros não são ainda conhecidos (Guerra e Nodari, 2004). Segundo Calixto (2000), estima-se que até o momento apenas em torno de $10 \%$ da biodiversidade mundial tenha sido estudada. Ainda assim, cerca de 140 mil metabólitos intermediários, oriundos, sobretudo, de plantas superiores, já foram isolados e caracterizados. Ainda, segundo este autor, estima-se que $40 \%$ dos medicamentos disponíveis na terapêutica moderna tenham sido desenvolvidos a partir de fontes naturais: $25 \%$ de plantas, $13 \%$ de microorganismos e $3 \%$ de animais.

O Brasil é o país com maior diversidade biológica do mundo. Estima-se que o Brasil tenha mais de $22 \%$ do total de espécies vegetais e um terço das espécies de pássaros do planeta (Calixto, 2000). No entanto, esta diversidade encontra-se ameaçada pela crescente destruição e uso indiscriminado dos ambientes naturais e seus produtos. Espécies e populações estão sendo perdidas a taxas sem precedentes, ao mesmo tempo em que a biota global está se tornando homogeneizada, devido à introdução de espécies exóticas em novas regiões (Mooney et al., 2005). 
Soma-se a este um outro aspecto muito importante que é a perda do conhecimento, acumulado por milênios, sobre o uso medicinal tradicional das plantas destes ambientes pelas populações a eles associadas. O folclore e a medicina tradicional destas populações são de grande importância para reduzir o tempo gasto em atividades de bioprospecção. Porém, a devastação das florestas provoca a migração dessas comunidades, normalmente para centros urbanos, rompendo o fluxo de conhecimento adquirido e acumulado ao longo do tempo (Guerra e Nodari, 2004).

$\mathrm{Na}$ maioria dos países ricos em biodiversidade - normalmente com abundância de florestas pluviais - a simples derrubada das matas para utilização das terras em atividades agrícolas e pecuaristas têm sido a principal alternativa. A exploração de produtos florestais não madeireiros (PFNM), quando existente, se dá de maneira inadequada e/ou predatória. Os PFNM (em geral frutos comestíveis, óleos, látex, fibras, plantas medicinais) servem de matéria-prima para várias indústrias, como a farmacêutica, alimentícia, de cosméticos e produtos naturais, por exemplo. Além disso, Wilson (1994: 328) relata que, em 1989, estudos demonstraram que os PFNM da Amazônia peruana não só são mais lucrativos a longo prazo, mas são consideravelmente mais lucrativos do que a derrubada pura e simples das árvores.

No Brasil, a Floresta Amazônica, devido à sua fundamental importância para o equilíbrio ambiental e como fundamental fonte de biodiversidade, tem sido foco de atenção da comunidade internacional. Dentre as medidas adotadas pelo governo federal para desacelerar o processo de degradação deste bioma tão importante, está a criação e o fortalecimento de diferentes modelos de unidades de conservação, dentre as quais se incluem as Reservas Extrativistas (RESEX). As RESEX surgiram como uma alternativa de atenuar o problema fundiário de concentração de terra, promover a exploração dos recursos naturais de forma sustentável e de conservar a biodiversidade no território amazônico (Reydon e Maciel, 2003). O manejo sustentável e o uso de práticas corretas de exploração da biodiversidade, incluindo questões como adoção de "selos verdes", acesso legal à biodiversidade e partição de benefícios com a comunidade local - detentora do conhecimento tradicional -, permitem agregar um sobrepreço aos produtos gerados com estas variáveis.

É sabido que, muitas vezes, a certificação é utilizada apenas como estratégia de marketing e não como ferramenta para melhorar a gestão florestal. Além disso, os objetivos adicionais para certificação podem ser: mudar ou fortalecer a imagem, diminuir o perigo de sabotagem de grupos de protesto, melhorar a credibilidade sobre assuntos relativos ao desmatamento florestal (nos casos de Indonésia e Brasil, por exemplo) e usar os eco-selos como ferramentas eficientes da política ambiental (dos gover- nos) (Unicamp/CIRAD, 2001). Por outro lado, a crescente conscientização quanto à destruição e degradação dos recursos naturais tem influenciado a população no sentido de exigir que suas compras de produtos derivados das florestas, como madeiras, frutos, entre outros, não contribuam para agravar esse quadro, mas, ao contrário, auxiliem a assegurar os recursos florestais para o futuro. Neste sentido, os programas de certificação têm participação importante não só para auxiliar o marketing das empresas junto a seus clientes, mas também para contribuir para o manejo sustentável que satisfaça as necessidades sociais, econômicas, ecológicas, culturais e espirituais das gerações presentes e futuras (Unicamp/CIRAD, 2001).

De qualquer maneira, o verdadeiro desafio não é a mera criação das reservas extrativistas ou de outras formas de unidades de conservação, e sim como integrar a extração sustentável e demais práticas naturais de gerenciamento florestal nas estratégias de produção das propriedades rurais existentes, sejam elas grandes ou pequenas, responsáveis pela maior parte da devastação que assola as florestas pluviais amazônicas. Fundamentalmente, o problema não é onde e como dispor de parte das florestas, e sim como preparar pessoas para melhor gerenciá-las (Browder apud Wilson, 1994).

Entretanto, tais aspectos devem considerar a dinâmica do processo de inovação, para que conservação ambiental e desenvolvimento econômico, social e tecnológico possam caminhar juntos e não sejam elementos conflitantes. $\mathrm{O}$ item a seguir procura mostrar de que forma o desenvolvimento e implementação de inovações, sejam estas organizacionais ou tecnológicas, são fundamentais para que estratégias competitivas empresariais que visam o uso sustentável da biodiversidade obtenham êxito.

\section{O uso sustentável da biodiversidade: uma oportunidade para estratégias competitivas}

Muitas empresas têm procurado integrar os princípios e práticas do desenvolvimento sustentável em seu contexto de negócio, conciliando as dimensões econômica, social e ambiental da sustentabilidade à exploração do potencial da biodiversidade de modo a obter ganhos e benefícios. É neste contexto que se inserem, por exemplo, as atuais estratégias de algumas empresas que atuam no mercado de produtos naturais e ambientalmente corretos, as quais vêm procurando acompanhar e aproveitar o uso econômico desta riqueza no desenvolvimento de novas trajetórias tecnológicas abertas por este mercado.

A exploração da questão ambiental tem se baseado no aproveitamento de fatores competitivos como ativos intangíveis (notadamente marca) e comerciais (marketing, canais de distribuição), diversificação de mercado, diferenciação de produtos e, não menos importante, o de- 
senvolvimento de novos insumos (essências, extratos, princípios ativos), entre outros (Garcia et al., 2003). Isso tudo requer inovação não somente em P\&D, mas também organizacional - desde a gestão de recursos humanos até a gestão de "ativos ambientais" - e, necessariamente, a consideração do arcabouço legal-regulatório para subsidiar as diferentes estratégias e a tomada de decisão.

As diferentes formas de organizar a produção e incorporar novos conceitos e paradigmas têm impactos significativos sobre a capacidade de reação a mudanças no ambiente competitivo, identificação de oportunidades de lucro e ação estratégica. É nesse contexto que a incorporação da variável ambiental e do conceito de desenvolvimento sustentável requer mudanças organizacionais, adaptação e/ou substituição de processos produtivos, adequação e/ou antecipação a normas ambientais e de segurança. Todo este processo acarreta custos para a empresa e exige estruturas de governança adequadas para implementar a nova estratégia. As estratégias são a base da competitividade e podem ser definidas como o conjunto de gastos em gestão, recursos humanos, produção e inovação, segmentação e diferenciação que visam ampliar e renovar a capacitação de empresas nas dimensões exigidas pelos padrões de concorrência vigentes nos mercados de que participam (Ferraz et al., 1996).

Nesse sentido, as estratégias estão condicionadas pelo ambiente competitivo, no qual são definidos os padrões de concorrência e pela capacitação dos recursos internos das firmas (Jank et al., 1999). Os padrões de concorrência são constituídos por variáveis que mudam ao longo do tempo, como resposta a mudanças institucionais (abertura comercial, proteção à propriedade industrial, nova regulamentação), mudanças tecnológicas (biotecnologia, avanço em técnicas de bioprospecção, etc.), mudança no ambiente competitivo (reestruturação industrial, mudanças no hábito e exigências do consumidor) e mudanças nas próprias estratégias individuais das empresas que buscam criar assimetrias e quando bem sucedidas podem alterar o padrão de concorrência ao serem imitadas por concorrentes (Jank et al., 1999).

A eficiência de uma determinada estrutura de governança é primariamente determinada pela sua capacidade de resposta às mudanças. Por sua vez, as oportunidades de lucros extraordinários estão justamente no desequilíbrio provocado por mudanças no ambiente econômico. O aproveitamento das oportunidades de lucro, crescimento ou qualquer que seja o objetivo da organização depende de sua capacidade de adaptação às mudanças. Segundo Azevedo (1997), mudanças no meio ambiente não antecipadas pelos agentes vão implicar modificação das transações existentes, revisão de contratos e mesmo modificação da forma organizacional. A reestruturação das transações existentes implica custos de transação, poden- do-se aqui entender o maior impacto de uma regulamentação excessivamente burocrática do acesso a recursos genéticos nas atividades de pesquisa e desenvolvimento em biodiversidade, por exemplo.

O outro aspecto desta ligação nos permite acreditar nas potencialidades e oportunidades de ganho proporcionadas pelo uso da diversidade biológica dentro dos preceitos da sustentabilidade ambiental pelo setor produtivo. Azevedo (1997) argumenta que as oportunidades de lucro econômico surgem, sobretudo, de situações em que o mercado ainda não atingiu o seu equilíbrio. $\mathrm{O}$ acontecimento de contingências imprevistas - regulamentação ambiental, exigências do consumidor, barreiras à exportação de produtos que agridam o meio ambiente, inovação tecnológica, etc. - cria a oportunidade de lucro àqueles que mais rapida e eficientemente se adaptarem às mudanças.

Além disso, a abordagem evolucionista do desenvolvimento econômico preconiza que a competitividade das empresas decorre principalmente da capacidade em gerar e difundir inovações, sendo necessário o constante aprimoramento das competências inovativas a fim de dotar as firmas de melhores condições para modificar ou reagir às mudanças no mercado (Rosenberg, 1976; Nelson e Winter, 1982; Dosi e Orsenigo, 1988; Dosi e Malerba, 1996; Perez, 2002). Além disso, inovações de produto e processo podem servir para melhorar o desempenho ambiental das empresas e, ao mesmo tempo, fazer com que estas obtenham vantagens como redução de custos, aumento da produtividade e exploração de novos mercados garantindo-lhes assim posições competitivas à frente da concorrência (Porter e van der Linde, 1995). Nesse sentido, a biodiversidade brasileira revela grandes oportunidades não só para a pesquisa e desenvolvimento de novos produtos, como também para a adoção de novas estratégias competitivas em consonância com a crescente pressão para a diminuição do impacto das atividades industriais sobre o meio ambiente. Reconhece-se, assim, que o dinamismo, a flexibilidade, a rentabilidade e a inovatividade do setor produtivo são necessários para se alcançar o desenvolvimento sustentável e que a geração de capacidade de gestão e de recursos técnicos e financeiros é indispensável à solução dos problemas ambientais (Corazza, 1996).

Algumas organizações, como o World Business Council for Sustainable Development (WBCSD), a World Conservation Union (IUCN) e a Earthwatch Europe têm se dedicado a desenvolver e divulgar documentos que esclareçam o setor produtivo sobre suas responsabilidades com relação ao desenvolvimento sustentável e à conservação da biodiversidade, ancorados nas diretrizes da Convenção sobre Diversidade Biológica (CDB, 2005). Aberta para assinatura durante a Conferência das Nações Unidas sobre Meio Ambiente e Desenvolvimento em 1992, a CDB 
apresenta as diretrizes orientadoras aos países para a regulamentação dos mecanismos de conservação e acesso à biodiversidade, assim como para a repartição dos benefícios advindos de sua exploração; dessa forma, os países signatários passaram a ter que elaborar e regulamentar normas, diretrizes, estratégias específicas para este tema. Além disso, estas organizações procuram conscientizar o setor produtivo sobre de que maneira estas responsabilidades podem se reverter em vantagens competitivas e oportunidades de lucro. De forma sintética, procuram colocar a biodiversidade como uma prática corporativa, identificar as questões corporativas referentes à biodiversidade e fornecer orientações para o desenvolvimento de ações corporativas pró-biodiversidade (Abbott et al., 2002).

Estes documentos mostram de que forma a CDB pode afetar os mais variados setores da indústria restringindo seu acesso a recursos biológicos, impondo restrições ambientais e comerciais, influenciando financiadores e stakeholders. Também atentam para a necessidade das empresas desenvolverem uma política de biodiversidade que esteja integrada em todos os estágios de ciclo de vida dos produtos, processos ou serviços em consonância com a política nacional de meio ambiente e de biodiversidade, cuja elaboração e implementação devem ser acompanhadas ativamente pelo setor produtivo a fim de impedir que seja aprovada uma legislação excessivamente burocrática ou mesmo inviável de ser seguida (Abbott et al., 2002; Stone et al., 1997).

Além disso, destacam a importância dos recursos genéticos como matéria-prima e oportunidades de negócios para diversos setores da indústria, como a farmacêutica, agrícola, florestal, alimentícia e cosmética, e mostram de que forma a exploração sustentável destes recursos pode se reverter em maiores ganhos - como redução de custos, melhoria na imagem, aumento no faturamento -, do que os métodos de exploração convencionais. Apresentam exemplos de empresas que têm investido no segmento de produtos naturais - muitas vezes com a colaboração de comunidades locais e unidades de manejo -, que possuem programas bem sucedidos de certificação de áreas florestais e de políticas ambientais sérias e efetivas (Abbott et al., 2002; Stone et al., 1997).

De acordo com Stone et al. (1997), as atividades de bioprospecção bem estruturadas são uma esperança para os esforços futuros de conservação e desenvolvimento. Quanto maior o número de negócios envolvidos nesse tipo de atividade - principalmente nos setores farmacêutico, alimentício e de cosméticos - acredita-se que mais avanços tecnológicos serão obtidos, com resultados mais eficientes (Abbott et al., 2002). Com relação à obtenção de recursos naturais como matéria-prima, por exemplo, tem-se avançado em questões como a gestão ou mane- jo florestal sustentável, ou seja, no reflorestamento, na conservação dos habitats originais, no manejo da erosão genética, e na gestão total de um infindável ciclo natural sustentável.

O Brasil, sendo um país megadiverso, tem um potencial enorme a ser explorado seguindo esta tendência de aproveitamento da biodiversidade para obtenção de produtos naturais, farmacêuticos, cosméticos, alimentícios, entre outros, aliada à conservação ambiental, principalmente se considerarmos que muito pouco ainda se sabe sobre essa biodiversidade. Algumas empresas já atentaram para isso e vêm procurando incorporar às suas rotinas e cultura internas os preceitos do desenvolvimento sustentável no delineamento de novas estratégias, desenvolvimento de novos produtos e exploração de novos mercados. O próximo item apresenta quatro casos nacionais.

\section{Algumas estratégias empresariais de uso sustentável da biodiversidade}

A fim de ilustrar os argumentos desenvolvidos no presente artigo, são apresentados os casos de quatro empresas: Ybios, Centroflora, Orsa Florestal e Natura, sendo a primeira uma empresa de identificação de novas oportunidades de uso de produtos naturais e gestão de projetos de bioprospecção, resultado de uma joint-venture das três últimas empresas. Essa amostra se justifica por ser a Ybios uma empresa com uma proposta inovadora, tendo sido concebida por empresas de diferentes áreas de atuação que têm em comum a incorporação dos princípios da sustentabilidade e o interesse na exploração do potencial da biodiversidade brasileira. Outro ponto interessante é o fato de cada uma das empresas controladoras da Ybios estar estrategicamente localizada em diferentes pontos da cadeia produtiva de produtos naturais (sejam cosméticos, nutracêuticos, fitoterápicos ou manejo florestal), sendo a Ybios uma espécie de elo em P\&D.

O estudo foi feito a partir da coleta de dados primários. As quatro empresas foram visitadas e realizadas entrevistas com gerentes e/ou diretores pertencentes às áreas de P\&D, Jurídica e de Desenvolvimento Sustentável. As entrevistas consistiram em torno de 20 questões objetivas e subjetivas e procuraram explorar em maior profundidade aspectos como a política corporativa, a relação com clientes e fornecedores, processo de internacionalização, atuais tendências e estratégias (de mercado, de gestão da pesquisa, desenvolvimento e lançamento de novos produtos, de desenvolvimento de novos insumos e de responsabilidade ambiental) e vantagens e limitações encontradas no uso sustentável da biodiversidade. Complementarmente, foram levantados dados secundários em publicações especializadas da mídia (jornais, revistas, entre outros), e, especialmente, em publicações acadêmicas, como relatórios de pesquisa, artigos, entre outros, 
assim como em websites. Também foram consultados publicações e material de divulgação das empresas, assim como de associações a que pertencem.

As informações coletadas foram compiladas de modo a permitir a caracterização das estratégias de cada uma das quatro empresas. A descrição destas estratégias segue abaixo. Posteriormente, foram levantados os aspectos comuns a cada estratégia, permitindo assim uma análise global de como essas empresas têm inserido o uso sustentável da biodiversidade em suas estratégias competitivas.

\subsection{Ybios}

Um exemplo interessante e ímpar no Brasil é a criação da Ybios, uma joint-venture entre o Grupo Centroflora, Natura e Orsa Florestal que tem como principal negócio - segundo seu site institucional - "a gestão de pesquisas por meio da criação de redes de competência, tendo em vista o uso sustentável da biodiversidade" (Ybios, 2005). O foco da Ybios é em alimentos funcionais, cosméticos e fitomedicamentos, tendo como base o uso da biodiversidade. A empresa foi oficializada em setembro de 2004, depois que seus sócios identificaram no mercado um grande gargalo a ser explorado: o grande distanciamento entre o setor acadêmico e a indústria. Segundo um dos diretores da empresa, a motivação de sua criação foi, portanto, “... a necessidade de se agregar valor e conhecimento aos investimentos em $\mathrm{P} \& \mathrm{D}$ e viabilizar uma maior relação entre universidades e setor produtivo".

Dentre os projetos que a Ybios se propõe a fazer estão a prospecção de novas oportunidades de negócio a partir do conhecimento disponível no setor acadêmico ou da demanda do mercado, a identificação de competências, laboratórios e pesquisadores, a montagem de redes de pesquisas, a busca por investidores e a negociação com os agentes, pesquisadores e empresas. Os pesquisadores são considerados as competências externas da empresa, as quais são identificadas em publicações, congressos e seminários, visitas técnicas às instituições e contatos pessoais. Dessa forma, a empresa gera uma espécie de banco de dados sobre "quem faz o que e onde".

Dentre os fatores de maior relevância para a competitividade da empresa estão: o prazo de execução do projeto, a inovação de produto/processo, a capacitação em gestão e, principalmente, a confiabilidade com relação à segurança da informação e a transparência nas relações, o que requer antes de tudo, expertise na elaboração de contratos. Dessa forma, a estratégia competitiva da empresa se caracteriza especialmente pelo oferecimento de serviços diferenciados e inovadores, pela melhoria contínua na qualidade dos serviços e da assistência aos clientes, pela capacitação em formação e gestão de redes de P\&D e pela temática abordada, ora seja a biodiversidade e a sustentabilidade.
O uso sustentável da biodiversidade está pautado na idéia de usar os recursos sem causar seu esgotamento. A empresa lida com dois processos paralelos: a pesquisa e o desenvolvimento de produtos. Para tanto, a exploração da matéria-prima não pode ser feita de maneira predatória. Dessa forma, paralelamente às diferentes fases de desenvolvimento do produto - agronômica, químico-farmacêutica e biomédica - a empresa busca planejar de que forma se dará a exploração da matéria-prima, seja por meio de manejo sustentável, cultivo, reprodução em laboratório e assim garantir sua disponibilidade quando este produto estiver no mercado. Também é necessário definir quem fará a exploração, quem usará a tecnologia de obtenção desenvolvida e que comunidades locais serão inseridas no projeto.

A Ybios não realiza a produção, apenas licenciando patentes ao final de um projeto de desenvolvimento. "As possíveis patentes já têm a sustentabilidade amarrada à sua forma de produção. As diversas cláusulas e pré-requisitos são colocados no contrato de licenciamento do produto para que o comprador as siga", afirmou o diretor entrevistado. A empresa possui uma política definida de acesso ao patrimônio genético e repartição de benefícios.

Dentre as dificuldades apontadas na operacionalização da estratégia da empresa, está a necessidade de se fazer um contrato exclusivo com cada cliente ou parceiro, devido às particularidades de cada um e ao despreparo, principalmente das universidades, no estabelecimento de parcerias com o setor privado. Outro ponto é a legislação de acesso a recursos genéticos, a qual afeta diretamente a Ybios, uma vez que a empresa trabalha com gestão de projetos de bioprospecção.

\subsection{Centroflora}

Fundado em 1957, o Grupo Centroflora atua na produção e fornecimento de extratos vegetais secos e aquosos, tinturas e polpas vegetais nacionais e também importados. Consiste nas empresas Centroflora (1957), Anidro (1993) e Vegeflora (1972) (Grupo Centroflora, 2005). As empresas do Grupo Centroflora se inserem na cadeia produtiva de diferentes indústrias, uma vez que fornecem produtos para a indústria cosmética, farmacêutica e alimentícia. São empresas chamadas de "primeira transformação", as quais fazem o processamento da matéria-prima para posterior fornecimento a empresas responsáveis pelo produto final (indústria processadora). A maior parte da produção é voltada para o mercado externo, que responde por $70 \%$ do faturamento da empresa.

Para o grupo, os fatores de competitividade de maior relevância são a diferenciação dos produtos e serviços oferecidos, a inovação de produtos e processos, a capacitação tecnológica e a sustentabilidade ambiental. Os extratos produzidos pelo Grupo Centroflora são largamente 
utilizados na produção de produtos naturais, cujo consumo vem aumentando significativamente nos últimos anos (Batalha e Ming, 2003). Além disso, o grupo, em sua homepage oficial, aponta como seu principal objetivo, atualmente, "atingir a total sustentabilidade ambiental de suas matérias-primas (...) através do estabelecimento de parcerias com pequenos produtores rurais, para o cultivo de espécies de interesse, ou através de parcerias com comunidades locais, visando o manejo sustentado de espécies nativas" (Grupo Centroflora, 2005). O grupo aponta as linhas de alimentos funcionais - nutracêuticos - e de produtos farmacêuticos como as mais atraentes para a empresa no momento, pois têm oferecido maior retorno.

Em 2003 o grupo iniciou o programa "Parcerias para um mundo melhor". A principal motivação para a sua criação reside na preocupação com a garantia de disponibilidade da matéria-prima. Dentro desse programa, temse procurado fazer com que os clientes ajudem a promover a sustentabilidade. No entanto, ainda não é possível para o grupo adotar esta conduta em $100 \%$ dos produtos, embora, em volume, em torno de $60 \%$ da produção já esteja inserida. A maior dificuldade é incluir as plantas importadas. Além disso, há produtos cuja demanda ainda é pequena e irregular, portanto não comporta economicamente esse tipo de trabalho.

Os investimentos para a implementação da estratégia se concentraram principalmente na relação e estabelecimento de parcerias com clientes e no planejamento e controle da produção, incluindo o estabelecimento de parcerias com produtores e também a consultoria de ONGs. O Imaflora e o Instituto Biodinâmico (IBD) são os responsáveis pela certificação. Atualmente, $95 \%$ dos produtos são certificados. Devido a esta política, foi necessário ampliar a área de Botânica e Sustentabilidade do grupo, que tem como principal objetivo desenvolver fontes de matéria-prima sustentáveis. Além disso, o Grupo Centroflora mantém diversos projetos sócio-ambientais, os quais contam com a participação de funcionários do grupo, comunidades locais e empresas parceiras. Para promover e apoiar estes projetos, o grupo criou uma ONG, o Instituto Floravida (Grupo Centroflora, 2005).

Um outro ponto importante na estratégia é a confiabilidade das informações sobre a matéria-prima utilizada. Além do conhecimento tradicional associado, busca-se o conhecimento científico. Considera-se inviável comercializar um produto derivado de plantas medicinais sem que se tenha conhecimento a respeito da dosagem, princípio ativo e demais especificações. Este processo demanda consultas a especialistas, pesquisas internas e em parceria. $\mathrm{O}$ grupo possui um setor de $\mathrm{P} \& \mathrm{D}$ em que são desenvolvidas atividades nas áreas dos três mercados de atuação da empresa. São pesquisados potenciais produtos a partir da matéria-prima. A empresa investe em torno de 1,5 a 2,0\% do faturamento em P\&D e a tendência é aumentar nos próximos anos. Para acompanhar a fronteira tecnológica dos principais produtos do grupo, há um setor específico, o qual cuida das relações institucionais entre o departamento de $\mathrm{P} \& \mathrm{D}$, a empresa e as universidades e pesquisadores. Além disso, o grupo destaca a joint venture para a criação da Ybios.

Dentre as vantagens apontadas pela empresa na adoção da estratégia de uso sustentável da biodiversidade estão o aumento no número de clientes, na capacidade de economizar recursos e da competitividade; a valorização do produto, a otimização do processo produtivo, a conservação da matéria-prima; e, principalmente, a melhoria da imagem da empresa. A empresa tem no uso sustentável da biodiversidade um de seus pilares. O grupo pretende continuar com a estratégia de sustentabilidade, uma vez que considera se tratar de uma tendência mundial.

\subsection{Natura}

A Natura é líder do mercado brasileiro de cosméticos, respondendo por 18,9\% deste. Já no mercado desde 1969 , seus produtos são vendidos por meio da venda direta, realizada por aproximadamente 526 mil revendedoras em todo o País e no exterior. Suas vendas cresceram $33 \%$ em 2004 e $117 \%$ nos últimos três anos. O volume de negócios em 2005 foi R \$ 4,4 bilhões, alta de 27,3\% em relação a 2004. (Natura, 2005). Grande parte deste crescimento se deve ao investimento que a empresa vem realizando na criação de uma nova plataforma tecnológica baseada no uso sustentável da biodiversidade brasileira, na internacionalização de seus negócios e em mudanças operacionais as quais envolvem fornecedores, parcerias com comunidades locais, ONGs, governos e o setor acadêmico.

Com o lançamento da linha Ekos em 2000, a Natura entrou no mercado dos chamados "produtos naturais". Os produtos dessa linha são produzidos com extratos advindos da biodiversidade brasileira obtidos preferencialmente de forma sustentável. A Natura investiu inicialmente $\mathrm{R}$ \$ 11 milhões no desenvolvimento e lançamento da linha, em 2000. Inicialmente, a linha contava com 7 famílias de ativos de insumos da biodiversidade. Em 2004 já eram 15 famílias de ativos, gerando cerca de 70 produtos (Almeida, 2004). A opção pela biodiversidade brasileira como plataforma tecnológica e a incorporação de práticas de responsabilidade ambiental foi um movimento determinante dos resultados conquistados recentemente pela Natura. Só a linha Ekos foi responsável por 10\% do faturamento total da empresa em 2002, gerando um negócio de cerca de $\mathrm{R} \$ 200$ milhões anuais (Vassallo, 2003). O volume de negócios da empresa em 1999, antes do lançamento da linha Ekos, foi de US\$ 657 milhões. Em 2004 este valor foi de US\$ 1,2 bilhão, ou seja, praticamente dobrou. A linha Ekos está sendo o "carro chefe" para a 
entrada da Natura no mercado europeu, uma vez que esses produtos atraem bastante o consumidor internacional. O investimento inicial de lançamento da marca e abertura da primeira loja, em abril de 2005 em Paris, foi de US\$ 20 milhões. A Natura também mantém negócios na América Latina. Exporta para a Argentina, Chile, Peru, Bolívia e, mais recentemente, México (Natura, 2005).

Para garantir a sustentabilidade na extração dos insumos vegetais, a Natura estabeleceu parceria com o Instituto Biodinâmico (IBD) e a Imaflora, ONG que representa no Brasil o FSC (Forest Stewardship Council) e implementou o "Programa de Certificação de Ativos Naturais ou Vegetais". Trata-se de um instrumento que promove o manejo sustentável de áreas florestais e de cultivo, envolvendo critérios do FSC e do SAN (Sustaintable Agriculture Network) (Pastor, 2000). Do ponto de vista da gestão, a empresa busca incorporar cada vez mais ao cotidiano dos negócios os princípios do desenvolvimento sustentável. A anterior adoção das orientações da Global Reporting Iniciative, GRI, e a consolidação em 2004 do Sistema de Gestão de Responsabilidade Corporativa são passos nessa direção. Um resultado recente desse movimento foi a incorporação das dimensões social e ambiental ao mapa estratégico e ao balanced scorecard da companhia. Em 2004, a Natura obteve a certificação ambiental pela norma ISO 14001 (Natura, 2005).

Não só a Natura como o setor em que ela atua depende do lançamento constante de novos produtos, justificando os altos investimentos em inovação observados no setor. Além disso, a venda direta exige um intenso ritmo de lançamentos, para fazer com que as consultoras tenham novidades para entrar em contato com suas clientes (Nascimento e Marx, 2001). Para tal, a Natura construiu um centro de $P \& D$, que é hoje o maior da América Latina. Os investimentos da empresa em inovação atingiram R \$ 67 milhões em 2005, uma alta de 41,5\% em relação a 2004. O Quadro 1 mostra alguns dados relativos a P\&D na empresa em 2004. A fim de conseguir renovar seu portfolio de produtos - em torno de 600 - com grande rapidez, a Natura mantém de 80 a 100 projetos de novos produtos simultâneos, tipicamente envolvendo de 5 a 10 pessoas em cada um (Nascimento e Marx, 2001).

Em 2006 a Natura criou uma nova área - gestão de parcerias e inovação tecnológica - e lançou o Programa Natura Campus de Inovação Tecnológica 2007, o qual visa otimizar a gestão do relacionamento com universidades, centros de pesquisa e demais empresas voltadas à pesquisa a fim de formar redes de parcerias e prospectar novas oportunidades de negócio, aumentando assim a quantidade e intensidade tecnológica das inovações geradas pela empresa. Um portfolio de projetos feitos com essas instituições, tendo como foco principal a aplicação do conhecimento sobre a flora brasileira na indústria cos-
Quadro 1 - Perfil e resultados do investimento da Natura em P\&D em 2004 (número, R\$ milhões e \%).

\begin{tabular}{lcc}
\hline \multicolumn{1}{c}{ Itens } & Unidade & Resultado \\
\hline Lançamentos* & número & 182 \\
\hline $\begin{array}{l}\text { \% do faturamento proveniente de pro- } \\
\text { dutos lançados/relançados em 2004 e }\end{array}$ & $\%$ & 63 \\
2003 & & \\
\hline $\begin{array}{l}\text { Investimento da receita líquida em } \\
\text { P\&D }\end{array}$ & milhões & 47,7 \\
\hline $\begin{array}{l}\text { Investimento da receita líquida em } \\
\text { P\&D ** }\end{array}$ & $\%$ & 2,7 \\
\hline $\begin{array}{l}\text { Solicitação de patentes no Brasil } \\
\text { Concessão de patentes de invenção e } \\
\text { desenho industrial no Brasil e no ex- } \\
\text { terior }\end{array}$ & & 15 \\
\hline
\end{tabular}

*Em 2003, foram 117 lançamentos e em 2005, 213; e **A meta é aumentar este valor para mais de 3\%. Fonte: Natura (2005).

mética, está na origem das inovações introduzidas nas diversas linhas de produtos da companhia. Dentro do programa Natura Campus 2003, desenvolvido em parceria com a Fundação de Amparo à Pesquisa do Estado de São Paulo (Fapesp), por exemplo, foram assinados sete contratos com universidades paulistas (Natura, 2005). Em 1999, a Natura comprou por R \$ 20 milhões o laboratório Flora Medicinal, fundado no Rio de Janeiro em 1912. Com isso, incorporou um vasto acervo sobre a flora brasileira, ampliando fontes de matéria-prima para produtos futuros, principalmente no segmento de fitoterápicos (Arnt, 2001).

A matéria-prima utilizada nos produtos da linha Ekos é fornecida por comunidades tradicionais extrativistas, grupos de agricultura familiar e assentamentos agrícolas. No entanto, a Natura não compra diretamente destas comunidades, havendo empresas intermediárias - geralmente grandes empresas - responsáveis pelo contrato com as comunidades e pelo processamento, refinamento físico e químico e padronização da matéria-prima para que possa ser então vendida à Natura. Há assim uma rede de fornecedores intermediários prioritários que atendem às exigências da Natura com relação ao modelo de relacionamento com as comunidades e de obtenção de ingredientes para a linha Ekos. Isto requer a elaboração de modelos de gestão da produção e inclusão de pequenos fornecedores - por meio da criação e fortalecimento da cadeia produtiva - e a adaptação dos fornecedores intermediários, uma vez que a oferta deste tipo de matéria-prima não é constante, dependendo de períodos de safra.

Para evitar a super especialização ou a criação de uma relação de forte dependência das comunidades com a Natura, a empresa nunca pede exclusividade. Há a preocupação de não se criar a expectativa irreal nas comunidades de que a Natura possa ser a solução de todos os seus problemas. Para minimizar esta questão, a Natura 
possui planos de ação - como diagnósticos, consultorias - para promover o desenvolvimento sustentável local em algumas dessas comunidades e/ou melhorar a sua capacitação no negócio do fornecimento, como a certificação, por exemplo. Para tanto, estabelece parcerias com ONGs, secretarias municipais de meio-ambiente, IBAMA, sindicatos, enfim, stakeholders locais que conheçam e possam acompanhar de perto essas comunidades e promover efetivamente as melhorias necessárias. Além disso, para tentar sanar a questão do curto tempo de vida dos produtos cosméticos, a Natura sempre amplia ou renova os produtos derivados de uma mesma matéria-prima dentro da linha Ekos e também procura comprar sempre mais de um tipo de matéria-prima de cada comunidade.

Segundo relatório anual 2004 da empresa, dentre os objetivos estratégicos da Natura estão: ampliar a liderança no mercado nacional; aumentar investimentos e capacitação em P\&D; acelerar o processo de internacionalização; estreitar as relações com seus fornecedores; e aprimorar seus programas sociais e ambientais. Há também a intenção de ampliar o modelo de uso sustentável da biodiversidade para as demais linhas da empresa, o que é um processo lento e que depende da capacitação interna da empresa. Os maiores desafios são o processo de internacionalização e o aprimoramento na relação com as comunidades tradicionais.

\subsection{Orsa florestal}

A empresa Orsa Florestal faz parte do Grupo Orsa, fundado em 1981, o qual também compreende a Orsa Celulose, Papel e Embalagens; Jari Celulose e Fundação Orsa. Este conglomerado de empresas nacionais atua na área de papel e celulose, embalagens e, com a aquisição da Jari Celulose em 2000, passou a atuar na área de madeira certificada. A Orsa Florestal foi fundada em 2001 e começou a operar em 2003. A motivação de sua criação foi a aquisição da Jari, que possui uma área florestal de 1,7 milhão de hectares às margens dos rios Jari e Parú, na Amazônia oriental paraense. Apenas uma pequena parte, 50 mil hectares para uso e 50 mil de pousio, é utilizada para plantação de eucalipto para produção de celulose branqueada de fibra curta. Para explorar de maneira sustentável essa área florestal, foi criada a Orsa Florestal. A área de floresta nativa manejada é de 545 mil hectares. Tanto a área de floresta plantada quanto a de floresta nativa são certificadas pelo $F S C$.

A importância da Orsa dentro do grupo em termos de faturamento é mínima, pois se trata de uma empresa nova e pequena; ainda não gera lucros. Sua receita líquida foi de apenas R $\$ 13$ mil, embora o faturamento em 2004 tenha sido de US\$ 2,7 milhões. Entretanto, os trabalhos desenvolvidos pela Orsa Florestal, devido a seu conceito de sustentabilidade e relacionamento com comunidades, têm sido muito relevantes para a imagem do grupo.
Os principais produtos da empresa são os madeireiros. No entanto, há mais ou menos sete mil pessoas vivendo nas áreas da Jari Celulose, além das quatro cidades que estão dentro da área de influência da empresa. Assim, de modo a contribuir para o desenvolvimento econômico das comunidades locais e aproveitar melhor o potencial da floresta, a Orsa Florestal começou a desenvolver parcerias para a produção de produtos florestais não madeireiros (PFNM) (Grupo Orsa, 2005).

Além disso, os fatores de competitividade que têm maior relevância nos mercados em que a empresa atua são a qualidade e a diferenciação do produto e a sustentabilidade ambiental. Segundo o site oficial da empresa, seus objetivos são: "a produção de madeira tropical certificada, a partir do manejo sustentável de florestas nativas na Amazônia; atender a uma demanda internacional crescente por produtos de madeira com garantia de origem; desenvolver atividades econômicas em parceria com as comunidades locais; atuar de forma ecologicamente correta, através da utilização racional e sustentável dos recursos naturais da região" (Grupo Orsa, 2005). Segundo os presidentes da empresa, esta foi criada dentro da concepção de uso múltiplo da floresta, valorizando-a em pé e valorizando os itens madeireiros - via manejo sustentável e certificação da extração - e não-madeireiros - orientando as comunidades locais para que consigam realizar o extrativismo de forma sustentável (Waack e Amoroso, 2005).

Como dito anteriormente, o manejo florestal é certificado pelo FSC. A área de 545 mil hectares é dividida em subáreas e cada subárea dividida de novo em unidades de manejo anuais. As unidades de manejo são de 30 anos. A lista de espécies com potencial comercial é encaminhada para aprovação pelo Ibama, que autoriza o manejo para cada ano, dentro do Programa Operacional Anual (POA). Segundo o gerente da Orsa, este processo "é muito burocrático, demorado e complicado".

A comunidade local tem licença de uso e exploração dos PFNM na área de manejo. Além disso, em algumas áreas específicas, há a doação de terras para comunidades, isso já está em processo de regularização fundiária e transferência de propriedade. Assim, o grupo, que possui uma fundação homônima responsável por desenvolver o trabalho junto às comunidades locais, realiza projetos de desenvolvimento comunitário e de adequação do extrativismo aos princípios da sustentabilidade. Há também uma tentativa de agregar valor aos PFNM, estimulando as comunidades a vendê-los em estado mais processado. A empresa não se envolve na parte de vendas dos PFNM, apenas ajuda na organização da comunidade e presta assistência jurídica.

Os investimentos realizados para dar suporte a esta estratégia se concentraram no processo de certificação, na 
internacionalização dos negócios da empresa e na adequação à legislação ambiental. $\mathrm{O}$ investimento inicial foi muito alto, embora o valor não tenha sido informado.

A Orsa Florestal não possui uma área de P\&D voltada para a área madeireira. São realizadas algumas pesquisas com PFNM - copaíba, andiroba -, contribuindo para pesquisas de universidades, fazendo parcerias para estudos de campo, mas sem pretensões científicas. A empresa tem parceria com a Centroflora para o desenvolvimento de corantes naturais a partir de madeiras nativas.

No entanto, a empresa tem se concentrado atualmente no levantamento de oportunidades de agregar mais valor à madeira cortada. Hoje ela possui uma serraria simples, que fornece a madeira em ripas, tábuas, mas sem nenhum processamento industrial. A idéia agora é dar mais passos no processo de agregação de valor. Também há a intenção de realizar parcerias com empresas locais de esquadrias e movelarias. Com isso a empresa pretende amenizar a dificuldade que o setor comercial tem hoje, que é o desconhecimento do mercado consumidor.

Os principais meios utilizados pela empresa para aquisição e desenvolvimento de novas tecnologias e mercados têm sido a joint venture para a criação da Ybios, convênios com universidades e/ou centros de pesquisa (Embrapa, Esalq, IPT) - para pesquisar sobre a possível utilização de determinados tipos de madeira e cooperação com outras empresas, como a Centroflora.

Os produtos da Orsa Florestal possuem sobrepreço e atendem principalmente ao mercado internacional (praticamente $100 \%$ das vendas), notadamente Holanda (87\%) e Alemanha (6\%). Segundo o gerente entrevistado, esses países exigem a certificação da madeira. Os principais clientes são empresas de construção civil, que necessitam de madeira resistente à água para a construção de diques. No Brasil (1,2\% das vendas), o mercado é totalmente resistente à madeira certificada devido ao sobrepreço embutido. Os clientes brasileiros não estão dispostos a pagar o preço exigido.

Para a empresa, as maiores vantagens da adoção deste tipo de estratégia são a melhoria da imagem da empresa e a possibilidade de atuação em novos nichos de mercado. Já os principais gargalos são o preparo da mão-de-obra - treinamento de identificadores florestais e de funcionários da área comercial -; a elevação de custos - madeira certificada é mais custosa -; e a legislação. Atualmente, o grande gargalo que a empresa vem enfrentando é a morosidade do processo de aprovação do POA pelo IBAMA. Isso está prejudicando não só a empresa, mas o setor. Além disso, as madeireiras ilegais continuam suas atividades normalmente.

A Orsa acredita que a incorporação do desenvolvimento sustentável em seus negócios é muito mais que uma tendência e sim uma necessidade. Algo que a empresa tem procurado colocar em todos os fóruns de que participa é que a Amazônia pode ser auto-sustentável, pode gerar riquezas mantendo-se em pé e mantendo também as pessoas que habitam a região (em torno de 20 milhões). A empresa acredita que se houver consciência do valor da biodiversidade, da floresta, das pessoas e do conhecimento tradicional, a Amazônia pode sim ser conservada e isso pode trazer muito mais recursos para o Brasil.

\subsection{Aspectos comuns}

A apresentação dos casos das empresas Ybios, Centroflora, Natura e Orsa Florestal permitiu visualizar como vem se dando a operacionalização de estratégias baseadas no uso sustentável da biodiversidade, as quais estão inseridas nos modelos de negócio destas empresas. De maneira geral, pôde-se perceber que a incorporação do desenvolvimento sustentável está inserida na política de responsabilidade socioambiental das empresas, fazendo parte de sua estratégia corporativa e integrada - ou em processo de integração - a todos os setores da empresa. Como exemplo, há unidades gerenciais - sejam gerências ou diretorias - voltadas exclusivamente para elaboração de modelos que garantam progressivamente a sustentabilidade das ações das empresas. No caso da Ybios, a sustentabilidade é prevista até mesmo em contratos de propriedade intelectual e licenciamento de tecnologias.

Uma forma de garantir e também divulgar a incorporação dos princípios do desenvolvimento sustentável muito destacada pelas empresas estudadas é a certificação ambiental da própria empresa e de seus fornecedores e a adoção de selos verdes para os produtos. Confirma-se, assim, a tendência apontada no relatório Unicamp/CIRAD (2001). Outro aspecto muito importante na operacionalização da estratégia adotada pelas empresas estudadas é o estabelecimento de parcerias em diversas instâncias: desde a capacitação do fornecedor até o desenvolvimento de novos produtos. A fim de implementar modelos de gestão da produção e inclusão de pequenos fornecedores, as parcerias incluem ONGs, pequenos agricultores, comunidades extrativistas, órgãos do governo, lideranças locais, associações de classe, universidades e institutos de pesquisa. Só assim é possível viabilizar a sustentabilidade ao longo da cadeia produtiva, além de evitar a migração de comunidades tradicionais para o meio urbano e, conseqüentemente, evitar a perda do conhecimento tradicional, essencial para o estudo do potencial de uso da biodiversidade (Guerra e Nodari, 2004).

A geração constante de inovações - sejam tecnológicas ou organizacionais - parece ser outro aspecto chave em estratégias de uso sustentável da biodiversidade. Todas as empresas destacaram a importância de investimentos em atividades de P\&D e o desenvolvimento de competências no âmbito científico para aproveitar o potencial da biodiversidade de forma eficiente e garantir 
assim a agregação de valor aos seus componentes e, conseqüentemente, sua conservação. $\mathrm{O}$ distanciamento entre o setor acadêmico e a indústria é apontado como gargalo para que inovações sejam geradas com maior rapidez e eficiência, destacando-se a importância de programas de parceria em pesquisa entre estes setores a fim de formar redes de competência.

As empresas estudadas apontam a garantia de disponibilidade da matéria-prima como a principal motivação para a adoção deste tipo de estratégia. No entanto, sabese que ter associada à imagem da empresa a idéia de sustentabilidade cria importantes oportunidades de atuação no mercado externo, mais exigente no que diz respeito às questões ambientais (não por acaso, a Centroflora, Orsa Florestal e Natura têm grande interesse em aumentar seus negócios no exterior). De todo modo, são apontadas pelas empresas como principais vantagens da adoção dos preceitos do desenvolvimento sustentável a redução de custos a médio e longo prazo (esse tipo de estratégia demanda um alto investimento inicial em processos de certificação, consultorias, compra de matéria-prima diferenciada, etc.), maior eficiência na obtenção de matéria-prima e nos processos produtivos, melhoria da imagem da empresa, além da comercialização de um produto diferenciado - muitas vezes com possibilidade de sobrepreço - permitindo, assim, além da diferenciação de produtos, a diversificação dos mercados de atuação. As vantagens apontadas pelas empresas corroboram para os resultados das pesquisas realizadas por Garcia et al. (2003), Abbott et al. (2002) e Stone et al. (1997), assim como para os pontos levantados com relação à importância da criação de assimetrias para a obtenção de vantagens competitivas nos trabalhos de Jank, et al. (1999) e de Porter e van der Linde (1995).

\section{Considerações finais}

A partir da análise dos casos acima apresentados, é possível perceber que a incorporação da variável ambiental e do conceito de desenvolvimento sustentável requer mudanças organizacionais, adaptação e/ou substituição de processos produtivos a fim de garantir a manutenção e disponibilidade dos recursos utilizados, adequação e/ou antecipação a normas ambientais e de segurança. Tudo isso implica em vultosos investimentos e capacitação em inovação, seja esta tecnológica ou organizacional, interna ou em parceria. Não restam dúvidas de que a inovação é elemento chave para que se possa atingir o desenvolvimento sustentável. Produtos com características específicas (matérias-primas alternativas, ambientes e modos de produção inovadores, embalagens especiais) demandam grande esforço de $P \& D$, uma vez que a sustentabilidade não será atingida com pa- drões menos exigentes que os demandados para produtos convencionais (Waack e Amoroso, 2005).

Além disso, levar em consideração a forma como os atores do sistema de inovação interagem e como se dá a interação destes com o arcabouço regulatório e institucional que está sendo elaborado no País é condição sine qua non para que os custos sejam condizentes com o contexto que se pretende construir, assim como para garantir a manutenção do aumento da competitividade atrelada à exploração sustentável da biodiversidade por parte de diferentes empresas interessadas neste tipo de estratégia. Propriedade intelectual, distribuição de resultados entre os agentes envolvidos (das comunidades às universidades e empresas), garantias de impactos controláveis em ambientes complexos como as florestas são desafios de grande vulto. A difusão horizontal dessas inovações é crítica para ganhos de escala e mudanças institucionais (Waack e Amoroso, 2005).

No entanto, não se pode esquecer da importância e da urgência de políticas públicas capazes de incentivar uma postura ambientalmente responsável por parte da indústria nacional. Nesse sentido, são imprescindíveis as pressões da comunidade, consumidores, segmentos organizados da sociedade civil, os quais são fortes instrumentos de iniciativas tanto de auto-regulamentação das empresas quanto de política ambiental pública. Afinal, a eficácia de uma política pública ambiental depende, em grande parte, do grau de importância que a sociedade atribui às questões ambientais e também dos instrumentos e da maneira como eles se articulam entre si e com as demais políticas públicas, como de ciência e tecnologia, energia, educação, transportes, recursos hídricos, entre outras (WCED, 1987; Barbieri, 1997).

Como se pode ver, a conservação da biodiversidade tem sua importância constatada por seus desdobramentos econômicos, sociais e ambientais, na agregação de valor a produtos e processos e na criação de novas oportunidades de empregos e de mercados, principalmente para os países que a possuem. Nesse sentido, faz-se imprescindível a adoção de medidas destinadas a preservar e conservar este patrimônio e seus diferentes ecossistemas. Estas medidas não necessariamente se contrapõem ao crescimento e desenvolvimento econômico. Pelo contrário, o conceito de desenvolvimento sustentável vem fortalecer a possibilidade de conciliar a conservação do meio ambiente e a produção de riqueza e bem estar para a sociedade. Segundo Wilson (1994), "a minimização das taxas de extinção e a minimização dos custos econômicos são compatíveis: quanto mais as outras formas de vida forem conservadas, mais produtiva será e mais garantida estará a nossa própria espécie". 
ABBOTT, C.; PORTE, C. A.; BARRINGTON, R.; BERTRAND, N.; CAREY, C.; FRY, A.; PRAG, A.; VORHIES, F. As empresas e a biodiversidade: Um Manual de Orientação para Ações Corporativas. Earthwatch Institute (Europe), International Union for conservation of Nature and Natural Resources, World Business Council for Sustainable Development. Ed. ATAR Roto Presse SA, Suíça. 2002.

ALMEIDA, H. Óleos amazônicos conquistam o mundo: indústria oleoquímica trabalha a todo vapor para atender interesse mundial por essências da floresta brasileira. Química e Derivados Edição no 429, agosto de 2004.

ARNT, R. Tesouro Verde. Exame, ano 35, n. 9, maio. 2001.

AZEVEDO, P. F. A Nova Economia Institucional. In: FARINA, E. M. Q.; AZEVEDO, P. F.; SAES, M. S. M. Competitividade: mercado, estado e organizações. Ed. Singular, São Paulo, SP. 1997.

BARBIERI, J. C. Desenvolvimento e Meio Ambiente: as estratégias de mudanças da Agenda 21. Petrópolis, RJ, Ed. Vozes, $3^{\text {a }}$ edição. 1997.

BATAlHA, M. O.; MING, L. C. (coords.) Plantas medicinais e aromáticas: um estudo de competitividade no estado de São Paulo. São Paulo: Sebrae; São Carlos-SP: GEPAI; Botucatu-SP: Unesp. 2003.

CALIXTO, J. B. Biopirataria. Ciência Hoje, v. 28, n. 167, 2000.

CDB - CONVENÇÃO DA DIVERSIDADE BIOLÓGICA Homepage oficial. Disponível em: www.biodiv.org. Acesso em abril de 2005.

CORAZZA, R. I. Inovação tecnológica e demandas ambientais: notas sobre o caso da indústria brasileira de papel e celulose. 1996. (Mestrado) DPCT, IG, Unicamp. Campinas, SP.

DOSI, G.; MALERBA, F. Organizational learning and instituitional embeddedness. In: DOSI, G. e MALERBA, F. (orgs.). Organization and Strategy in the Evolution of the Enterprise. Londres: MacMillan, p. 1-24, 1996.

DOSI, G.; ORSENIGO, L. Coordination and transformation: an overview of structures, behaviors and change in evolutionary environments. In: DOSI, G. et al. (orgs) Technical change and economic theory, London: Pinter Publishers, 1988.

EHRLICH, P. R.; WILSON, E. O. Biodiversity studies: science and policy. Science, v. 253, agosto. 1991.

FERRAZ, J. C.; KUPFER, D.; HAGUENAUER, L. Made in Brazil. Ed. Campus, 386 p.
GARCIA, R.; SALOMÃO, S.; GUERRERO, A. Cosméticos, Perfumaria e Higiene Pessoal: Relatório Setorial Preliminar. Diretório da Pesquisa Privada. FINEP, Unesp, Unicamp. São Paulo. Mimeo. 2003.

GERAQUE, E. Repartição de Benefícios. Agência Fapesp, 15 de fevereiro de 2006. Disponível em http://www.agencia.fapesp.br. Acesso em fevereiro de 2006.

GRUPO CENTROFLORA. Homepage institucional. Disponível em http://www.centroflora.com.br/index.php. Acesso em novembro de 2005.

GUERRA, M. P.; NODARI, R. O. (2004) Biodiversidade: aspectos biológicos, geográficos, legais e éticos. In: Simões, C. M. O. et al. (orgs) Farmacognisia: da planta ao medicamento. $5^{\text {a }}$ ed. Editora da UFRGS, Editora da UFSC. Porto Alegre/Florianópolis.

JANK, M. S.; FARINA, E. M. Q.; GALAN, V. B. O agribusiness do leite no Brasil. PENSA/Editora Milkbizz. São Paulo, SP. 1999.

MMA - MINISTÉRIO DO MEIO AMBIENTE. Homepage institucional. Disponível em: http://www.mma.gov.br/ port/conama/index.cfm. Acesso em fevereiro de 2005.

MOONEY, H.; CROPPER, A.; REID, W. Confronting the human dilemma: how can ecosystems provide sustainable services do benefit society? Nature, v. 434, p. 561-562. 31 de março de 2005.

NASCIMENTO, P. T. S.; MARX, H. O Sistema de Inovação da Natura. V SEMEAD: Estudo de caso/ Operações. Junho de 2001.

NATURA. Homepage institucional. Disponível em: http:// www.natura.net/port/index.asp. Acesso em novembro de 2005.

NELSON, R.; WINTER, S. An evolutionary Theory of Economic Change. Havard University Press, Cambridge, MA. 1982.

NOVAES, W. Os custos da biodiversidade. O Estado de São Paulo, 9 de agosto de 2002.

NOVAES, W. Ainda no mesmo barco. O Estado de São Paulo, 12 de março de 2004.

PASTOR, L. Natura lança linha ecologicamente correta. O Estado de São Paulo, 10 de agosto de 2000.

PEREZ. C. Technological revolutions and finacial capital - The Dinamics of Bubbles and Golden Ages. Northampton: Edgar Elgar. 2002.

PORTER, M. E.; VAN DER LINDE, C. Verde e Competitivo: Acabando com o Impasse. In: PORTER, M. E. Competição: estratégias competitivas essenciais. $3^{\mathrm{a}} \mathrm{ed}$. Rio de Janeiro, Editora Campus, p. 371-397. 1995. 
REYDON, B. P.; MACIEL, R. C. G. Valoração econômico-ambiental de uma alternativa produtiva na Reserva "Chico Mendes". Instituto de Economia, Unicamp, Campinas. Disponível em: www.eco.unicamp.br/projetos/gestao_ambiental/gestaoambiental.html. Acesso em outubro 2003.

ROSENBERG, N. Perspectives on Technology. Cambridge: Cambridge University Press. 1976.

STONE, D.; RINGWOOD, K.; VORHIES, F. Business and Biodiversity: a guide for the private sector. World $\mathrm{Bu}-$ siness Council for Sustainable Development (WBCSD), International Union for Conservation of Nature and Natural Resources (IUCN). Junho, 1997.

UNICAMP/CIRAD. Fortalecimento das atividades extrativistas no Acre. Brasília: CIRAD, 2001. Mimeo.
VASSALO, C. Um jeito diferente de fazer negócios. Revista Exame. Editora Abril. São Paulo, ed. 787, ano 37, n. 5, p. 32-40. 12 de março de 2003,

WAACK, R. S.; AMOROSO, S. Desenvolvendo Sustentabilidade. Parcerias Estratégicas. Centro de Gestão e Estudos Estratégicos. Edição Especial: n. 20 (Pt. 1), junho de 2005 .

WCED Our common future: the world commission on environment and development. Oxford:, Oxford University Press, 420p.

WILSON, E. O. Diversidade da vida. Tradução: Carlos Afonso Malferrari São Paulo: Cia das Letras.

YBIOS Homepage institucional. Disponível em http:// www.ybios.com.br. Acesso em novembro de 2005.

\title{
TECHNOLOGICAL OPPORTUNITIES AND COMPETITIVE STRATEGIES OF ENVIRONMENTAL MANAGEMENT: THE SUSTAINABLE USE OF THE BRAZILIAN BIODIVERSITY
}

\begin{abstract}
Biodiversity has been considered a strategic element due to, among other reasons, its potential as a raw material provider to many industry sectors. Nevertheless, the increasing degradation of the environment threatens this potential and therefore the urgency in promoting sustainable development. Motivated by this context, many companies are adopting, as part of their competitive strategies, the sustainable use of biodiversity so as to take advantage of new technological opportunities open in the environmentally responsible products market. Thus, the purpose of the present paper is to analyze how some Brazilian companies are using the potential of biodiversity as part of their competitive strategies in order to create favorable market asymmetries. It also acknowledges the advantages and limitations concerning this strategy. To illustrate these opportunities, this work presents the case of four national companies which work in the Brazilian environmentally responsible products market, focusing on phytoterapics, cosmetics, natural extracts and forestry. This study has pointed out that incorporating sustainable development principles does not seem to be simply a temporary strategy, but a strong tendency especially to industry sectors highly dependent on biodiversity as a raw material. Other issues addressed include the relevance of innovation to the generation of new proceedings and technologies as well as the importance of the conformation of a solid institutional environment.
\end{abstract}

Keywords: technological innovation, sustainable development, natural products, competitive strategies, environmental accountability. 
